\title{
A Study on Japanese Visual-Audio-Oral Course Construction
}

\section{Haiyan Liang}

Japanese Department, School of Foreign Language, East China University of Science and Technology, Shanghai, China Email: hyl@ecust.edu.cn

How to cite this paper: Liang, H.Y. (2020) A Study on Japanese Visual-Audio-Oral Course Construction. Open Access Library Journal, 7: e6903.

https://doi.org/10.4236/oalib.1106903

Received: October 14, 2020

Accepted: November 6, 2020

Published: November 9, 2020

Copyright $\odot 2020$ by author(s) and Open Access Library Inc.

This work is licensed under the Creative Commons Attribution International License (CC BY 4.0).

http://creativecommons.org/licenses/by/4.0/

\section{(c) (i) Open Access}

\begin{abstract}
The Japanese Visual-audio-oral Course is one of the core courses for senior students of Japanese majors. It aims to make the use of "visual" and "audio" training as input and "oral" training as output. The three abilities are complementary and conducive to promote students' comprehensive Japanese skills, insight into Japanese politics, economics and culture and global vision. The paper proposes the necessity and goal for Japanese Visual-audio-oral Course construction, analyzes approaches to enhancing Japanese Visual-audio-oral textbook edition and network teaching platform building and illustrates the effect and significance of the course construction. Ultimately the paper emphasizes that the reform of Japanese Visual-audio-oral Course is an effective attempt to cultivate talents with general knowledge and innovation and enhance the comprehensive ability of students of Japanese majors.
\end{abstract}

\section{Subject Areas}

Studies in Japanese Language Teaching

\section{Keywords}

Japanese Visual-Audio-Oral Course, Course Construction Goal, Effect, Significance

\section{1. 引言}

目前我国高校日语专业《日语视听说》课程的开设, 长期以来一般都采 取以教材为依托、局限于单一的课本录音教学式的传统模式, 而忽视了对学 生进行 “视” “听” “说” 实际应用能力的培养。在高度信息化的时代, 这 种传统的, 即通过 “讲解单词、泛读课文、播放录音” 等方式展开的课堂教 学模式不仅已很难满足学生对知识的渴求, 而且大大降低了课堂教学的吸引 
力, 导致学生对专业课学习缺乏主动性。因而, 高年级的 “视听说” 课程应 顺应新时期的教学要求, 打破那种只会做选择题的应试教育的旧模式, 即迫 切需要在以 “提高学生综合语言运用能力和文化素养” 为主要教学目标的基 础上构建全新的教学理念及其模式 [1]。

\section{2. 日语视听说课程建设的目标}

《日语视听说》是日语专业教学高年级课程设置中的重要核心课程之一, 也是专门为高等院校日语专业三年级以上学生开设的一门日语能力应用类核 心课程。《日语视听说》课程建设有利于促使学生进一步提高听说能力, 加 深对日本社会、文化等的认识, 从而启发学生在语言基本知识学习的基础上 逐步掌握高难度日语, 培养其高度的日语理解力和实际应用能力, 最终达到 提高其综合语言文化素养的目的。因此, 立足于通识教育视野, 充分探究《日 语视听说》课程建设、教学改革的方向和目标, 对于培养通识型日语专业人 才具有极其重要的实践意义。

在充分强调日语语言基本功学习的基础上, 本课程建设的目标具体设定 如下:

1) 能听懂日本人用普通话以正常语速所做的演讲、谈话等, 并要求理解 正确、能复述其中心内容。对电视节目, 现场采访的电视广播等讲话要求理 解正确、并能复述归纳其主要内容和重要情节。

2) 通过有选择地编辑录制 NHK 卫星综合节目内容, 每周实时补充提供 给学生新内容, 在促使学生视听说能力进一步提高的同时, 加深对日本社会、 文化、风土人情等的真实认识, 从而启发学生逐步掌握高难度日语, 培养其 高度的日语理解力和实际应用能力, 进而提高其综合语言素质。

总而言之, 要注重 “说” 能力的培养。以 “视” 与 “听” 为输入、“说” 为输出, 三种能力相辅相成, 最终达到提升学生语言综合运用能力的目的, 帮助学生了解日本社会政治、经济、文化、外交等动向, 并逐步形成 “国际 化视野”。

\section{3. 日语视听说课程建设的举措}

\section{1. 编著日语视听说教材}

在教学过程中, 深感我们中国学生迫切需要适合中国学生学习的日语教 材, 尤其是在缺少语言环境的情况下学生非常需要能够有效提高日语视听说 能力的教材。目前教材市面上与日语视听说有关的教材大多内容陈旧, 有的 是单纯的日剧片断, 有的是单一的新闻视听, 而且训练手段和练习设计也比 较简单机械, 要么是单纯地做选择题, 要么是再加一些听写填空。这些作为 单项训练的材料自然可以, 但作为一门课程的教材则显得过于单薄。有感于

此, 编者在长期的教学过程中, 积极致力于视听材料的积累和选编、以及训 练手段的思考和实践。在此基础之上将自身多年的教学经验融入其中, 最终 形成了这本日语视听说教材, 分《日语视听说教程 1》[2]《日语视听说教程 2》 [3]两册, 分别于 2013、2014 年由上海交通大学出版社相继出版。再则, 经过 
近五年的教学实践之后, 《日语视听说教程 1 》的修订版已于 2020 年 8 月全 新再版。这套以 “听解日语新闻和理解日本文化” 为目的而开发的实践型视 听说教程, 其主要特点体现在以下四个方面。

1) 内容丰富、题材新颖(涉及政治、经济、社会、文化、教育、自然、 科技、地理、传统、风土人情、日常生活等各个方面, 信息量大, 旨在让学 习者达到提高听说能力和了解日本的双重目的)。

2) 听说兼顾, 重在视听(每本共设 16 课。每一课分为新闻和综合节目两 部分, 每部分都分成六大板块, 每个板块对应不同的训练内容和目标)。

3) 音像结合、耳目相助(学习者可以边听边看, 既能满足视觉学习型的 读者, 也适合听觉学习型读者的需要。对学习者来说, 画面的提示有助于快 速调动自身的知识储备或补充背景知识, 这可以说是图式理论的具体应用。 另一方面, 画面中显示的日本的自然风貌等也可以让学习者对日本有更加感 性的认识, 并有助于提高语言的理解和运用能力)。

4) 练习配套、实力增强(可供教师布置作业或学生自学自习用, 以便进 一步充实教学内容量, 充分提高视听说技巧训练效果)。

今后, 《日语视听说教程》仍将定期更新时事新闻, 增补社会文化部分, 进一步完善教材内容, 与时俱进, 按照新国标, 全面规划再版以满足全国日 语专业教学的需求。

\section{2. 搭建课程网络教学平台}

《视听说》课程顾名思义, 需结合头脑的信息输入系统及语言输出系统。 这两种系统的作用方式在性质上相异, 一个是被动性的, 而另一个是主动性的。

基于多媒体网络技术进行教学的网络课程是一种新型的教学模式, 与传 统的课堂教学相比, 它具有资源共享性, 学习的自主性, 课程结构的开放性, 学习的协作性等诸多特点。它既是对日语专业学生语言交际综合能力培养的 新的有效途径, 同时也对相关的日语教师们提出了实施创新教育的新要求。

本课程于 2018 年开始搭建网络教学平台, 目前已在华东理工大学多层次 信息化学习平台上系统建课。日语视听说网络平台由 “师资团队、教学课件、 视频学习、课程作业、交流天地” 五个部分组成。课程学习模式可概述为: 文字教材精学 + 网络课件学习 + 网上导学拓展 + 视频信息传输 + 网上 讨论与答疑 + 作业提交与反馈 + 模拟自测学习 + 课程评价体系等。在线 答疑、讨论问题、视频下载等, 学生们可以通过这一平台对该课程进行系统 的预习、复习, 甚至自学, 还可以在网上提交作业、自测练习、交流学习体 会及分享学习成果。同时, 针对本课程需求, 计划搭建课程内统一信息门户 框架, 统一身份认证管理, 实现系统单点登录, 为日语专业学生提供本课程 的信息服务和校际资源共享平台。

\section{4. 日语视听说课程建设的重点}

\section{1. 合理设计教学内容}

本课程分《日语视听说》(必修)和《高级日语视听说》(选修)两部分, 开 
在三年级一学年共两个学期(四年级也可以选课), 一学期 16 周 32 学时。课程 主要内容具体由以下两大部分组成。

1) 《日语视听说》(专业必修, 三年级<上>)

a) NHK 卫星综合节目 (采用每周最新录制的视频内容, 側重精听)

NHK おはょう日本(ニュース、特集、生中継等) +土曜すてき旅

b) 《日语视听说 1》(教科书部分, 側重 “视听说” 的语言模仿技巧训练) I (ニュース ) + II (土曜すてき旅)

2) 《高级日语视听说》(专业选修, 三年级<下>)

a) NHK 卫星综合节目(采用每周最新录制的视频内容, 侧重 “视听说” 技巧)

NHK おはよう日本(ニュース、特集、生中継等) + 小さな旅/自然百景

b) 《日语视听说 $2 》$ (教科书部分, 侧重复述归纳训练)

$\mathrm{I}($ ニュース) + II (小さな旅)/(自然百景)

总之, 由浅入深循序渐进, 两个学期的内容各有侧重。每堂课必须先完 成最新剪辑录制的以 NHK 时事新闻节目为主的视听内容, 再加上教科书对 应部分的导学, 余下部分则留作业。课堂上以视听、表达、技巧训练为主, 并随时进行课堂提问, 围绕内容适时展开课堂讨论, 同时检验听解效果, 及 时发现问题、解决问题, 鼓励学生即使提问。由于课堂上的训练时间有限, 结合技巧应用以每周编辑录制的视听课件内容讲解为主, 同时要求学生课前 课后积极配合课堂教学内容同步完成大量视听说配套练习。

\section{2. 有效活用《日语视听说教程》}

首先, 在教材编写上, 应十分注重听前预热环节, 以调动学生的相关知 识储备, 为听解环节做准备; 在听解部分的任务设置上力求做到由浅入深, 层层推进; 最后还有说话环节, 促使学生将听解内容运用于日语的口头表达。 尤其是每周的新闻时事的视听, 帮助学生掌握相关术语, 从语音的输入变成 语言的输出。通过本教材的学习, 学生不仅可以切实提高日语的听说能力, 还可以从中了解日本的社会和文化, 而这又可以反过来进一步促进学生对日 语的理解和运用。因而, 该教材自出版之后, 被很多学校采用并广受好评。

1) 本教材是以听解日语新闻和理解日本文化为目的的实践型视听说教 材, 适用于日语专业中高级以上水平的学习者, 以全新的理念和形式弥补了 同类教材的不足之处。

2) 本教材立足于国家 “十三. 五课程建设规划” 的要求, 密切联系教学 实际, 以新型的实用性内容为指导致力于建设和研究创新的日语视听说教学 法。内容丰富、题材新颖; 听说兼顾, 重在视听; 音像结合、耳目相助; 音 像结合、耳目相助; 练习配套、实力增强。

3) 结合教材相关内容, 课堂教学每周补充 NHK 卫星综合电视节目新内 容(时事新闻、社会文化、季节性多彩之旅等), 旨在把最新信息传递给学生, 并结合视听说技巧, 在促使学生视听说能力进一步提高的同时, 加深对日本 社会文化等的认识, 并启发学生逐步掌握高难度日语, 培养其高度的文化理 解力和日语语言综合实际应用能力。 


\section{3. 充分发挥网络教学平台的作用}

其次, 日语视听说网络教学课程平台的建成为提高教学效果发挥出了极 大的作用。

1) 学习时间、地点上的随心所欲。可以使学生能根据自身的需要灵活的 安排学习时间, 完全突破了学习在时间及地点上的种种限制, 可以在任何时 间、任何地点通过学院网络视频学习课程, 使学生真正掌握学习的自主权, 将更多的时间和精力用在学习上, 充分享受网络学习的乐趣。

2) 学习进度上的随意安排。传统教育在教学进度上是固定化、统一化的, 很难顾及个别学生的学习特点, 也不会因为某个学生的某个章节没有听懂就 把整个课程重新再讲一遍, 而网络教育平台的课件则完全不受任何限制, 对 于视听疑难问题可反复练习。

3）教师资源的共享。网络教育优势就是可以把各有专长的师资汇集到一 起, 也可把课程相关视频通过学院网站与其它大学共享, 加强校际间的交流 与合作, 共同提高专业教育水平。

4) 学习资源的进一步开拓。通过本网络教学平台, 还可以在有效利用现 有学习资源的基础上, 更广泛地开拓网络资源, 充分展现日语教学的亮点, 并使学生扩大眼界逐步形成 “国际化视野”。

\section{5. 日语视听说课程建设的效果及意义}

\section{1. 日语视听说课程的教学效果}

自 2006 年承担日语视听说课程教学以来, 本人一直致力于视听说课程教 学模式的建设与探究, 并在课堂实践中取得了显著的教学效果。新颖的教学 模式与内容对专业学生有很大的吸引力, 学生们的听视听说能力及学习积极 性显著提高, 每学期的课堂测评及问卷调查充分显示了学生们对日语视听说 课程建设的肯定与期待。而且, 多年来, 上述教学理念也在日语口译教学课 中得到了充分的实践与提升。

因此, 经过多年的课堂教学实践与拓展, 日语视听说教材与网络教学平 台并驾齐驱取得了良好的教学效果。首先, 由于内容新鲜丰富, 原本令人感 觉枯燥乏味的听说课变得生动有趣, 大大提高了学生练习听说的兴趣。其次, 学生逐步掌握了科学的视听说方法, 养成了良好的视听说学习习惯, 从而提 高了视、听、说三种整体能力。再则, 大量现实、生动、高清晰的影像学习 资料, 将课堂与日本社会生活紧密结合起来, 不仅给学生们提供了完善高级 的日语语言学习环境, 增强了对日本社会文化的了解, 也充分开阔了其知识 眼界。最后, 通过 “后作业” 的各种学习实践活动进一步拓展了学生们实际 运用日语的能力。

现在, 视听、表达、技巧训练, 随时灵活地展开课堂讨论等这些课堂教 学方式虽已逐步发挥出了视听说网络课程的教学效果, 但尤其值得强调的是: 注重每堂课加入最新剪辑录制的视频学习内容, 把最新相关信息传递给学生, 并即兴组织进行课堂讨论和场景模拟表演, 增加临场训练, 锻炼学生的应对 能力, 全方位提高学生作为 “社会人” 的综合素质, 这才是提高视听说课堂 
教学效果的根本。

\section{2. 日语视听说课程建设的意义}

经过多年的课堂教学实践, 日语视听说课程建设的意义可归纳成以下四 点。

1) 增强了实践性。从学生今后的就业趋向和发展规划的角度出发, 注重 教学资料选材的实践性, 并通过课堂教学, 帮助学生提前了解日本社会、政 治、经济、文化、外交等动向, 尤其是与中国相关的动态, 为他们提前接触 社会、适应社会提供最有效的实践指导及模拟平台。

2) 提高了时效性。一般认为课程教学改革的重要价值就在于能否与社会 相融合, 而时效性是评价课程教学改革的重要因素之一。本课程注重从 NHK 等网络媒体获取最新的时事热点资讯, 并严格选取符合我国国情意识标准的 内容, 不仅能有效地提高学生意识形态的正确性、学习的自觉性, 还能增加 课堂教学的趣味性, 进一步提高教学效果与教学质量。

3) 综合能力得到了培养。视听说课程的教学是为了提高学生的综合素 质, 培养实践创新应用型人才。教学模式结合了各种教学手段的综合应用, 如进行课堂讨论和场景模拟表演等, 即增加了临场训练机会又锻炼了学生们 的应对能力，并促使其语言综合素养得到进一步的提高。

4) 加强了师资梯队的建设。视听说课程建设最大的成果是形成了一支高 质量高水平的师资团队。从我校的具体结构情况来看, 即由陈雪老师负责前 期基础阶段的教学, 虞崖暖老师负责中高级听力部分的衔接, 为视听说课程 打下扎实的基础; 蒋青老师侧重由视听说向口译训练的过渡; 梁海燕老师则 具体负责视听说课程的教学与实践。

\section{6. 结语}

综上所述, 基于多媒体网络技术进行教学的《日语视听说》课程作为一 种新的课堂教学模式, 是对日语专业学生语言交际综合能力培养的新的有效 途径, 同时也对从事日语教学的第一线的老师们提出了实施创新教育的新要 求。

外语学习, “听说读写” 密不可分。“听” 不仅仅是一味地用耳朵听, 用眼睛观察肢体语言和环境因素也是 “听” ，而 “说” 也不仅仅是自我表达， 交流互动亦是 “说”, 以 “视” 与 “听” 为输入、 “说” 为输出, “视听说” 三种能力应相辅相成才能达到完美。

因此, 加快推进《日语视听说》课程建设、不断实施教学改革, 是实现 通识型创新人才培养、提高日语专业本科生综合素质的有效尝试。

\section{Conflicts of Interest}

The author declares no conflicts of interest regarding the publication of this paper.

\section{References}

[1] 杜微. 浅析深化日语教学改革[J]. 双语学习, 2017(8M): 80-81. 
[2] 梁海燕, 陈雪. 日语视听说教程 1 [M]. 2013/修订版. 上海: 上海交通大学出版 社, 2018.

[3] 梁海燕, 陈雪. 日语视听说教程 2 [M]. 上海: 上海交通大学出版社, 2014.

\section{Appendix (Abstract and Keywords in Chinese)}

\section{《日语视听说》课程建设探究}

摘要: 《日语视听说》课程是为日语专业高年级学生设置的核心课程之 一, 力求以 “视” 与 “听” 为输入、 “说” 为输出, 三种能力相辅相成, 促 使学生提高日语综合水平, 更深入地了解日本社会政治、经济、文化等内涵, 逐步形成 “国际化视野”。文章提出了视听说课程建设的必要性及建设目标, 探究了 “视听说教材编写” 与 “搭建网络教学平台” 这两种课程建设的举 措, 并论述了本课程建设所取得的效果及其意义, 最终强调 “推进《日语视 听说》课程教学改革, 是实现通识型创新人才培养、提高日语专业本科生综 合素质的有效尝试”。

关键词: 日语视听说, 课程建设, 目标, 效果, 意义 